\title{
Ethyl acetate extract from Asparagus cochinchinensis exerts anti-inflammatory effects in LPS-stimulated RAW264.7 macrophage cells by regulating COX-2/iNOS, inflammatory cytokine expression, MAP kinase pathways, the cell cycle and anti-oxidant activity
}

\author{
HYUN AH LEE ${ }^{1 *}$, EUN KYOUNG KOH ${ }^{1 *}$, JI EUN SUNG $^{1 *}$, JI EUN KIM $^{1}$, SUNG HWA SONG $^{1}$, DONG SEOB KIM ${ }^{1}$, \\ HONG JOO SON ${ }^{1}$, CHUNG YEOUL LEE ${ }^{2}$, HEE SEOB LEE ${ }^{3}$, CHANG JOON BAE ${ }^{4}$ and DAE YOUN HWANG ${ }^{1}$ \\ ${ }^{1}$ College of Natural Resources and Life Science/Life and Industry Convergence Research Institute, \\ Pusan National University; ${ }^{2}$ Gangrim Organics, Miryang, Gyeongsangnamdo 627-706; \\ ${ }^{3}$ College of Human Ecology, Pusan National University, Busan 609-735; ${ }^{4}$ Biologics Division, \\ Ministry of Food and Drug Safety, Cheongju, Chungcheongbukdo 361-951, Republic of Korea
}

Received October 8, 2015; Accepted July 27, 2016

DOI: $10.3892 / \mathrm{mmr} .2017 .6166$

\begin{abstract}
Asparagus cochinchinesis (A. cochinchinesis) is a medicine traditionally used to treat fever, cough, kidney disease, breast cancer, inflammatory disease and brain disease in northeast Asian countries. Although numerous studies of the anti-inflammatory effects of A. cochinchinesis have been conducted, the underlying mechanisms of such effects in macrophages remain to be demonstrated. To investigate the mechanism of suppressive effects on the inflammatory response in macrophages, alterations of the nitric oxide (NO) level, the cell viability, inducible nitric oxide synthase (iNOS) and cyclooxygenase-2 (COX-2) expression levels, inflammatory cytokine expression, the mitogen-activated protein kinase (MAPK) signaling pathway, cell cycle arrest and reactive oxygen species (ROS) levels were measured in lipopolysaccharide (LPS)-activated RAW264.7 cells following treatment with ethyl acetate extract from A. cochinchinesis root (EaEAC). RAW264.7 cells pretreated two different concentrations of EaEAC prior to LPS treatment exhibited no significant toxicity. The concentration of NO was significantly decreased in the EaEAC + LPS treated group compared
\end{abstract}

Correspondence to: Professor Dae Youn Hwang, College of Natural Resources and Life Science/Life and Industry Convergence Research Institute, Pusan National University, 50 Cheonghak-ri, Miryang, Gyeongsangnamdo 627-706, Republic of Korea

E-mail: dyhwang@pusan.ac.kr

*Contributed equally

Key words: Asparagus cochinchinesis, cyclooxygenase-2, nitric oxide, RAW264.7 cells, cytokines, cell cycle, reactive oxygen species with the vehicle + LPS treated group. A similar decrease in mRNA transcript level of COX-2, iNOS, pro-inflammatory cytokines [tumor necrosis factor- $\alpha$ and interleukin (IL)-1 $\beta$ ] and anti-inflammatory cytokines (IL-6 and IL-10) was detected in the EaEAC + LPS treated group compared with the vehicle + LPS treated group, although the decrease rate varied. Enhancement of the phosphorylation of MAPK family members following LPS treatment was partially rescued in the EaEAC pretreated group, and the cell cycle was arrested at the G2/M phase. Furthermore, the EaEAC pretreated group exhibited a reduced level of ROS generation compared with the vehicle + LPS treated group. Taken together, these results suggest that EaEAC suppresses inflammatory responses through inhibition of NO production, COX-2 expression and ROS production, as well as differential regulation of inflammatory cytokines and cell cycle in RAW264.7 cells. In addition, these results provide strong evidence to suggest that EaEAC may be considered as an important candidate for the treatment of particular inflammatory diseases.

\section{Introduction}

Asparagus cochinchinesis (A. cochinchinesis), a perennial herb belonging to the Liliaceae family, is widely distributed in China, Japan and Korea, and has been used as a traditional medicine in those countries for thousands of years (1). The root of A. cochinchinesis has long been considered a therapeutic drug due to its anti-inflammatory, diuretic, antiseptic, antitussive, antibacterial, nervine, sialogogue, antipyretic and stomachic effects, and is also administered in combination with other herbs as a medicine to treat lung disease, immune system-associated diseases and aging $(1,2)$.

The root of $A$. cochinchinesis contains 19 amino acids, polysaccharides, and $>20$ multi-functional compounds. These functional compounds include $\beta$-sitosterol (3), daucosterol (4), 
n-ethatriacontanoic acid (5), palmitic acid (6), 9-heptacosylene (7), smilagenin (8), diosgenin (9), sarsasapogenin-3-O - $\beta$-D-glucoside imidacloprid (10), 5-methoxy methyl furfural, yame sapogenin, diosgenin-3-O- $\beta$-D imidacloprid glycosides $(11,12)$, aspacochioside D (13), iso-agatharesinoside (14) and seven steroidal saponins (15). In addition, the polysaccharide composition of $A$. cochinchinesis roots is reported to have several therapeutic properties, including antioxidant and anti-aging properties (16-18), antibacterial-inflammatory effects (16), antitumor effects (19-21), blood sugar reducing activity (22) and improvement of cough $(23,24)$.

Previous studies have reported the anti-inflammatory activity of $A$. cochinchinesis extract. Secretion of the pro-inflammatory cytokine, tumor necrosis factor- $\alpha$ (TNF- $\alpha$ ), in lipopolysaccharide (LPS)-and substance P-stimulated mouse astrocytes was significantly inhibited by A. cochinchinesis extract (25). Aspacochinosides N, O and P extracted from ethanol-treated $A$. cochinchinesis decreased the nitric oxide (NO) concentration in LPS-stimulated BV-2 microglial cells (26). Furthermore, ethanol extract from A. cochinchinesis decreased the degree of ectopic edema, ear thickness, cytokine secretion TNF- $\alpha$ and interleukin (IL)- $1 \beta$ and myeloperoxidase activity in a skin inflammation-induced mouse model treated with 12-O-tetradecanoyl-phorbol-13-acetate, all of which are considered indicators of skin inflammation progression (27). A crude aqueous extract of $A$. cochinchinensis effectively inhibited TNF- $\alpha$-induced cytotoxicity (21), increased the spleen index and superoxide dismutase (SOD) activity and decreased malondialdehyde (MDA) in mice (1). A recent study reported the inhibitory effects of $A$. cochinchinensis in allergic asthma-associated airway remodeling. The standardized herbal formula PM014, which includes the roots of A.cochinchinensis, efficiently inhibited the number of total cells, eosinophils, neutrophils, macrophages and lymphocytes in the bronchoalveolar lavage fluid of cockroach allergen-induced mice (28). Meanwhile, LPS used to induce an inflammatory response, is recognized by toll-like receptors (TLRs) distributed on the membrane of macrophages. The engagement of the TLR results in a potent inflammatory response characterized by the release of inflammatory cytokines, NO production and cell cycle regulation through the activation of the MAPK signaling pathway. Therefore, these markers and pathways may be considered as key factors for the analysis of the inflammatory response, to identify novel drugs with anti-inflammatory properties (29). However, the underlying mechanism by which $A$. cochinchinensis exerts its anti-inflammatory effects in macrophages has not yet been clearly identified, even though the induction of inflammatory lung diseases including asthma, cystic fibrosis, emphysema, and chronic obstructive pulmonary disorder have been implicated in the activation of macrophages.

The present study investigated the fundamental mechanisms responsible for anti-inflammatory activities of ethyl acetate extract from A. cochinchinesis root (EaEAC) in LPS-induced RAW264.7 microphage cells.

\section{Materials and methods}

Preparation of EaEAC. Roots of A. cochinchinensis were collected from plantations in the Go-Chang county of North Jeolla (Korea) and were dried in a drying machine (model
FD5510S-FD5520S; IlShinBioBase Co., Dongducheon, Korea) at $60^{\circ} \mathrm{C}$. Voucher specimens of A. cochinchinensis (WPC-14-003) were deposited in the Functional Materials Bank of the PNU-Wellbeing RIS Center at Pusan National University (Pusan, Korea). Dry roots of A. cochinchinensis were reduced to powder using a pulverizer (model MF-3100S; Hanil Electric Group Co., Ltd., Seoul, Korea), followed by extraction of EaEAC at $50^{\circ} \mathrm{C}$ for $24 \mathrm{~h}$ in a fixed liquor ratio (solid powder of $A$. cochinchinensis/ethyl acetate solvent ratio, 1:10) using circulating extraction equipment (SHWB-30/45, Woori Science Instrument Co., Pocheon, Korea). Extract solutions were subsequently passed through a $0.4 \mu \mathrm{m}$ filter, and concentrated by vacuum evaporation and lyophilized using circulating extraction equipment (IKA Labortechnik, Staufen im Breisgau, Germany). Finally, the EaEAC powder was dissolved in dimethyl sulfoxide (DMSO; Duchefa Biochemie B.V., Haarlem, Netherlands) to $1 \mathrm{mg} / \mathrm{ml}$, then further diluted to the required concentration.

Free radical scavenging activity. The scavenging activity of 2,2-diphenyl-1-picrylhydrazyl (DPPH) radical was measured as previously described (30). Briefly, each $100 \mu 1$ sample in eight different concentrations of EaEAC (250-2,000 $\mu \mathrm{g} / \mathrm{ml})$ was mixed with $100 \mu$ DPPH (0.1 mM; Sigma-Aldrich; Merck Millipore, Darmstadt, Germany) in $95 \%$ ethanol solution or $100 \mu 195 \%$ ethanol solution, then incubated for $30 \mathrm{~min}$ at room temperature. The absorbance of the reaction mixture was measured at $517 \mathrm{~nm}$ using a VersaMax plate reader (Molecular Devices, LLC, Sunnyvale, CA, USA). The DPPH radical scavenging activity of the EaEAC was expressed as the percent decrease in absorbance relative to the control. The half maximal inhibitory concentration $\left(\mathrm{IC}_{50}\right)$ is defined as the concentration of substrate that causes a $50 \%$ loss in DPPH activity.

Cell culture. The RAW264.7 cell line used in the present study is an Abelson murine leukemia virus-transformed macrophage cell line, provided by the Korean Cell Line Bank (Seoul, Korea). RAW264.7 cells were cultured in Dulbecco's modified Eagle's medium (DMEM; Thermo Fisher Scientific, Inc., Waltham, MA, USA) containing $10 \%$ fetal bovine serum (FBS; cat. no. S001-01; Welgene, Gyeongsan, Korea), L-glutamine, penicillin, and streptomycin (Thermo Fisher Scientific, Inc.) in a humidified incubator at $37^{\circ} \mathrm{C}$ with $5 \% \mathrm{CO}_{2}$ and $95 \%$ air.

Cell viability assay. Cell viability was determined using the tetrazolium compound 3-[4,5-dimethylthiazol-2-yl]-2,5-diphenyltetrazolium bromide (MTT; Sigma-Aldrich; Merck Millipore). To determine cell viability, RAW264.7 cells were seeded at a density of $5 \times 10^{4}$ cells $/ 0.2 \mathrm{ml}$ and cultured for $12 \mathrm{~h}$ in a $37^{\circ} \mathrm{C}$ incubator. When the cells reached $70-80 \%$ confluence, they were either untreated (NC group), treated with vehicle (DMSO), or pretreated with 100 or $200 \mu \mathrm{g} / \mathrm{ml}$ EaEAC dissolved in DMSO for $2 \mathrm{~h}$. Cells were subsequently incubated for $24 \mathrm{~h}$ with $1 \mu \mathrm{g} / \mathrm{ml}$ LPS (derived from Escherichia coli, serotype 055:B5; Sigma-Aldrich; Merck Millipore), then the supernatants were discarded and $0.2 \mathrm{ml}$ fresh DMEM and $50 \mu \mathrm{l} \mathrm{MTT}$ solution [2 $\mathrm{mg} / \mathrm{ml}$ in phosphate-buffered saline (PBS)] was added to each well. Cells were incubated at $37^{\circ} \mathrm{C}$ for a further $4 \mathrm{~h}$. Formazan precipitate was dissolved in 
DMSO and the absorbance at $570 \mathrm{~nm}$ was read directly in the wells using a VersaMax plate reader (Molecular Devices, LLC). The morphological features of RAW264.7 cells in each treated group were also observed using an inverted light microscope [Leica Microsystems (Schweiz) AG, Heerbrugg, Switzerland].

Measurement of NO concentration. NO accumulation was measured in the cell culture medium using Griess reagent [1\% sulfanilamide, $5 \%$ phosphoric acid, $0.1 \% \mathrm{~N}$-(1-naphthyl) ethylenediamine dihydrochloride; Sigma-Aldrich; Merck Millipore] as described previously (31). Briefly, RAW264.7 cells were treated with EaEAC (100 and $200 \mu \mathrm{g} / \mathrm{ml})$ for $2 \mathrm{~h}$ followed by LPS $(1 \mu \mathrm{g} / \mathrm{ml})$ for $24 \mathrm{hr}$. Following the collection of the supernatant, each sample $(100 \mu \mathrm{l})$ was mixed with the same volume of Griess reagent and incubated at room temperature for $10 \mathrm{~min}$. The absorbance was read at $540 \mathrm{~nm}$ using a VersaMax microplate reader (Molecular Devices, Sunnyvale, CA, USA).

Analysis of intracellular ROS level. ROS levels in cells were measured by staining with 2',7'-dichlorodihydrofluorescein diacetate (DCFH-DA; Sigma-Aldrich, Merck Millipore), a cell permeable and nonfluorescent agent that can be deacetylated by intracellular esterases to nonfluorescent DCFH, and is converted to highly fluorescent 2',7'-dichlorofluorescein (DCF) in the presence of intracellular ROS. When the RAW264.7 cells reached $70-80 \%$ confluence, they were either untreated, treated with vehicle, or pretreated with 100 or $200 \mu \mathrm{g} / \mathrm{ml}$ EaEAC dissolved in DMSO for $2 \mathrm{~h}$. Cells were subsequently incubated for $24 \mathrm{~h}$ with $1 \mu \mathrm{g} / \mathrm{ml}$ LPS. Cells were then incubated with $25 \mu \mathrm{M}$ DCFH-DA for $30 \mathrm{~min}$ at $37^{\circ} \mathrm{C}$, before they were washed twice with PBS. Green fluorescence was visualized at x200 and x400 magnification using an Eclipse TX100 fluorescent microscope (Nikon Corporation, Tokyo, Japan).

Western blotting. When the RAW264.7 cells reached $70-80 \%$ confluence, they were either untreated, treated with vehicle, or pretreated with 100 or $200 \mu \mathrm{g} / \mathrm{ml}$ EaEAC dissolved in DMSO for $2 \mathrm{~h}$. Cells were subsequently incubated for $24 \mathrm{~h}$ with $1 \mu \mathrm{g} / \mathrm{ml}$ LPS. Total protein for western blotting was extracted from RAW264.7 cells using Pro-Prep Protein Extraction Solution (iNtRON Biotechnology, Seongnam, Korea), centrifuged at $11,000 \times \mathrm{g}$ for $5 \mathrm{~min}$, and quantified using a SMART bicinchoninic acid assay kit (Thermo Fisher Scientific, Inc.). Proteins were separated by 4-20\% sodium dodecyl sulfate-polyacrylamide gel electrophoresis for $2 \mathrm{~h}$ (30 $\mu \mathrm{g}$ per gel), then resolved proteins were transferred to nitrocellulose membranes for $2 \mathrm{~h}$ at $40 \mathrm{~V}$. After the blocking with 3-5\% skim milk in TNT solution (137 mM NaCl, $2.7 \mathrm{mM}$ $\mathrm{KCl}, 10 \mathrm{mM} \mathrm{Na}_{2} \mathrm{HPO}_{4}$ and $0.05 \%$ Tween-20) and incubating at room temperature for $1 \mathrm{~h}$, the membranes were incubated overnight at $4^{\circ} \mathrm{C}$ with the following primary antibodies: Anti-SAPK/JNK (cat.no.9252; dilution, 1:1,000; Cell Signaling Technology, Inc., Danvers, MA, USA), anti-phosphorylated (p-) SAPK/JNK (Thr183/Tyr185; cat. no. 9251; dilution, 1:1,000; Cell Signaling Technology, Inc.), anti-ERK1 (K-23; cat. no. sc-94; dilution, 1:1,000; Santa Cruz Biotechnology, Inc., Dallas, TX, USA), anti-p-ERK1/2 (Thr202/Tyr204; cat. no. 9101; dilution, 1:1,000; Cell Signaling Technology,
Inc.), anti-p38 mitogen-activated protein kinase (MAPK; cat. no. 9212; dilution, 1:1,000; Cell Signaling Technology, Inc.), anti-p-p38 MAPK (Thr180/Tyr182; cat. no. 9211; dilution, 1:1,000; Cell Signaling Technology, Inc.) and anti- $\beta$-actin (cat. no. A5316; dilution, 1:3,000; Sigma-Aldrich; Merck Millipore). Membranes were then washed with TNT solution and incubated with 1:1,000 diluted horseradish peroxidase (HRP)-conjugated goat anti-rabbit IgG (cat. no. 81-6120; Zymed; Thermo Fisher Scientific, Inc.) at room temperature for $1 \mathrm{~h}$. Blots were developed using Amersham ECL Select Western Blotting detection reagent (GE Healthcare Life Sciences, Chalfont, UK). Protein bands were visualized using the FluorChem ${ }^{\circledR}$ FC2 Imaging system (Alpha Innotech Corporation, San Leandro, CA, USA) and the band density was semi-quantified using the AlphaView Program (version, 3.2.2; Cell Biosciences, Inc., Palo Alto, CA, USA). The target protein expression levels of three samples from each group were analyzed in three separate western blot analyses.

Enzyme-linked immunosorbent assay (ELISA) for IL-6. The concentration of IL-6 secreted from RAW264.7 cells was determined using an IL-6 ELISA kit (cat. no. 431304; Biolegend, Inc., San Diego, CA, USA) according to the manufacturer's protocols. Briefly, RAW264.7 cells were treated with two different concentrations of EaEAC (100 and $200 \mu \mathrm{g} / \mathrm{ml})$ for $2 \mathrm{~h}$, followed by $1 \mu \mathrm{g} / \mathrm{ml}$ of LPS for $24 \mathrm{~h}$. Cell supernatant was collected and $100 \mathrm{ml}$ serial dilutions of the standard or the supernatant were added to a 96-well plate coated with anti-IL-6 antibody, then incubated for $2 \mathrm{~h}$ at room temperature. Following five washes with wash solution (PBS, $0.05 \%$ Tween-20, $\mathrm{pH}$ 7.4), $100 \mu \mathrm{l}$ avidin-HRP solution was added to each well, and the plates incubated at $37^{\circ} \mathrm{C}$ for $2 \mathrm{~h}$. Following five washes, $100 \mu \mathrm{l}$ substrate solution was added and the plate was incubated at $37^{\circ} \mathrm{C}$ for a further $30 \mathrm{~min}$. The reaction was terminated by the addition of $100 \mu 1$ stop solution $(2 \mathrm{~N}$ $\mathrm{H}_{2} \mathrm{SO}_{4}$ ) and the absorbance at $450 \mathrm{~nm}$ was determined with a VersaMax plate reader (Molecular Devices, LLC).

Reverse transcription-quantitative polymerase chain reaction (RT-qPCR) analysis for cytokine gene expression. The relative expression of inducible nitric oxide synthase (iNOS), cyclooxygenase-2 (COX-2), TNF- $\alpha$, IL-1 $\beta$, IL-6 and IL-10 mRNAs were measured by RT-qPCR as previously described (32). Total RNA was purified by removing media from each cultured sample and homogenizing the cells in RNAbee (cat. no. CS104; Tel-Test Inc., Friendswood, TX, USA). The isolated RNA concentration was then determined using a NanoDrop spectrophotometer (BioSpec-Nano, Shimadzu Scientific Instruments, Columbia, MD, USA). Total RNA (5 $\mu \mathrm{g})$ was used to synthesize cDNA in a reaction mixture consisting of oligo (dT) primers (500 ng; Invitrogen; Thermo Fisher Scientific, Inc.), $10 \mathrm{mM}$ deoxyadenosine, deoxycytidine, deoxyguanosine and deoxythymidine triphosphates, $0.1 \mathrm{M}$ dithiothreitol, 5X reaction buffer and $1 \mu \mathrm{l}$ Superscript II reverse transcriptase (200 U/ $\mu$ l; cat. no. 18064-014; Invitrogen; Thermo Fisher Scientific, Inc.). Thermal cycling conditions for reverse transcription consisted of $70^{\circ} \mathrm{C}$ for $10 \mathrm{~min}$ followed by $42^{\circ} \mathrm{C}$ for $50 \mathrm{~min}$. RNA was removed from cDNA samples using 3.2 U/ $\mu 1$ RNase H (cat. no. 18021071; Invitrogen; Thermo Fisher Scientific Inc.) at $37^{\circ} \mathrm{C}$ for $20 \mathrm{~min}$. In order to amplify 
target genes, $2.5 \mu 1 \mathrm{cDNA}, 10 \mathrm{pmol}$ specific sense and antisense primers (Macrogene Co., Seoul, South Korea), 5 U/ $\mu 1$ Taq polymerase $(0.2 \mu \mathrm{l}$; PCR Core kit; Roche Diagnostics, Basel, Switzerland), $2 \mathrm{mM}$ deoxynucleotide triphosphate (2.5 $\mu \mathrm{l})$, and $10 \mathrm{X}$ reaction buffer containing $15 \mathrm{mM} \mathrm{MgCl}$ $(2.5 \mu \mathrm{l})$ were combined. A thermal cycler (Perkin-Elmer, Inc., Waltham, MA, USA) was used to amplify target genes using the following parameters: A pre-denaturation step of $7 \mathrm{~min}$ at $94^{\circ} \mathrm{C}$, followed by $25-32$ cycles of $30 \mathrm{sec}$ at $94^{\circ} \mathrm{C}, 30 \mathrm{sec}$ at $62^{\circ} \mathrm{C}$, and $45 \mathrm{sec}$ at $72^{\circ} \mathrm{C}$ and a final post-elongation step of $7 \mathrm{~min}$ at $72^{\circ} \mathrm{C}$. The primer sequences for target gene expression identification were as follows: iNOS, sense 5'-CACTTG GAGTTCACCCAGT-3' and anti-sense, 5'-ACCACTCGTACT TGGGATGC-3'; COX-2, sense 5'-CAGGTCATTGGTGGA GAGGTGTATC-3' and anti-sense, 5'-CCAGGAGGATGG AGTTGTTGTAGAG-3'; TNF- $\alpha$, sense 5'-CCTGTAGCCCAC GTCGTAGC-3' and anti-sense, 5'-TTGACCTCAGCGCTG ACTTG-3'; IL-1 $\beta$, sense 5'-GCACATCAACAAGAGCTT CAGGCAG-3' and anti-sense, 5'-GCTGCTTGTGAGGTG CTGATGTAC-3'; IL-10, sense 5'-CCAAGCCTTATCGGA AATGA-3' and anti-sense, 5'-TTTTCACAGGGGAGAAAT CG-3'; IL-6, sense 5'-TTGGGACTGATGTTGTTGACA-3' and anti-sense, 5'-TCATCGCTGTTGATACAATCAGA-3'. The final PCR products were separated on $1 \%$ agarose gel and then visualized by ethidium bromide staining. The band signal for each sample was visualized using the AE-9000 E-Graph gel documentation system (ATTO Corporation, Tokyo, Japan) and the band density was quantified using Image Saver 5 software (version 5.0; ATTO Corporation). The experiment was repeated three times and all samples were PCR-analyzed in triplicate.

Cell cycle assay. The cell cycle was measured using a Muse ${ }^{\mathrm{TM}}$ Cell Cycle kit (cat. no. MCH100106; EMD Millipore, Billerica, MA, USA) according to the manufacturer's instructions. Briefly, RAW264.7 cells were divided into $100 \mathrm{~mm}^{2}$ dishes (2.5x10 ${ }^{6}$ cells/dish), then pretreated with 100 or $200 \mu \mathrm{g} / \mathrm{ml}$ of EaEAC for $2 \mathrm{~h}$. Following treatment with $1 \mu \mathrm{g} / \mathrm{ml}$ of LPS for $24 \mathrm{~h}$, cells from subset groups were harvested by centrifugation at 3,000 $\mathrm{x} g$ for $5 \mathrm{~min}$, then fixed with $70 \%$ ethanol at $-20^{\circ} \mathrm{C}$ for $3 \mathrm{~h}$. The fixed cells were washed with $1 \mathrm{X}$ PBS, then added to $200 \mu \mathrm{l}$ Cell Cycle Reagent. Following incubation at $37^{\circ} \mathrm{C}$ in a $\mathrm{CO}_{2}$ incubator for $30 \mathrm{~min}$, cell cycles were analyzed using a Muse ${ }^{\circledast}$ Cell Analyzer with the Muse 1.3.1 analysis program (EMD Millipore).

Statistical analysis. Statistical tests were performed using SPSS version 10.10 (SPSS, Inc., Chicago, IL, USA). One-way analysis of variance was used to identify significant differences between NC- and LPS-treated groups. Differences in the responses of the Vehicle + LPS treated group and EaEAC + LPS treated groups were evaluated using a post hoc Tukey's test. All values are reported as the mean \pm standard deviation. $\mathrm{P}<0.05$ was considered to indicate a statistically significant difference.

\section{Results}

Anti-oxidant activity of EaEAC. The anti-oxidant activity of EaEAC was measured by DPPH scavenging analysis.

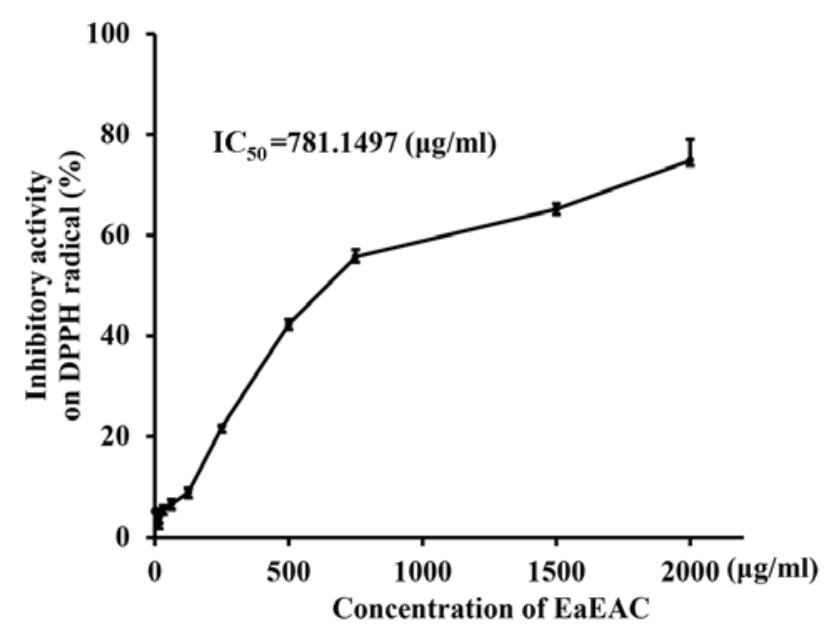

Figure 1. Free radical scavenging activity of EaEAC.DPPH radical scavenging activity was assayed in a mixture containing $0.1 \mathrm{mM} \mathrm{DPPH}$ and a range of concentrations of EaEAC (250-2,000 $\mu \mathrm{g} / \mathrm{ml})$. DPPH, 2,2-diphenyl-1-picrylhydrazyl radical; $\mathrm{IC}_{50}$, half maximal inhibitory concentration; EaEAC, ethyl acetate extract from Asparagus cochinchinesis root. Values are presented as the mean \pm standard deviation of three replicates.

Scavenging activity of EaEAC against DPPH radical was increased in a dose-dependent manner, with an $\mathrm{IC}_{50}$ of $781.1497 \mu \mathrm{g} / \mathrm{ml}$ (Fig. 1). This indicated that EaEAC exhibited DPPH radical scavenging activity.

Toxicity of EaEAC. To determine the toxicity of EaEAC, cell viability was measured by MTT assay. No marked differences in morphological features (Fig. 2A) or significant changes to cell viability (Fig. 2B) were observed in RAW264.7 cells treated with 100 and $200 \mu \mathrm{g} / \mathrm{ml} \mathrm{EaEAC}$ for $24 \mathrm{~h}$ compared with $\mathrm{NC}$ or vehicle group cells, indicating EaEAC is not toxicity at concentrations up to $200 \mu \mathrm{g} / \mathrm{ml}$.

Effects of EaEAC on NO production, iNOS and COX-2 expression. To examine the anti-inflammatory properties of EaEAC, alterations in NO concentration, and iNOS and COX-2 transcription were measured in LPS-stimulated RAW264.7 cells following EaEAC pretreatment. The concentration of $\mathrm{NO}$ was significantly increased in the vehicle + LPS-treated group compared with the NC group ( $\mathrm{P}=0.01$; Fig. $3 \mathrm{~A})$. However, the concentration of NO decreased by 18 and $33 \%$ in cells pretreated with 100 and $200 \mu \mathrm{g} / \mathrm{ml}$ EaEAC, respectively, with the concentration in the cells that were pretreated with $200 \mu \mathrm{g} / \mathrm{ml}$ EaEAC significantly reduced compared with the vehicle + LPS group ( $\mathrm{P}=0.002$; Fig. $3 \mathrm{~A})$.

Similarly, increased levels of iNOS and COX-2 mRNA expression were detected in the vehicle + LPS-treated group compared with the $\mathrm{NC}$ group $(\mathrm{P}=0.011$ and $\mathrm{P}=0.001$, respectively; Fig. 3B). However, these levels were reduced by $21 \%(\mathrm{COX}-2)$ and $33 \%$ (iNOS) in LPS-stimulated RAW264.7 cells that were pretreated with $200 \mu \mathrm{g} / \mathrm{ml}$ of EaEAC compared with the vehicle + LPS group $(\mathrm{P}=0.012$ and $\mathrm{P}=0.003$, respectively; Fig. $3 \mathrm{~B}$ ). EaEAC pretreatment was, therefore, demonstrated to inhibit the increase of $\mathrm{NO}$ concentration, and COX-2 and iNOS mRNA expression in LPS-activated RAW264.7 cells. 

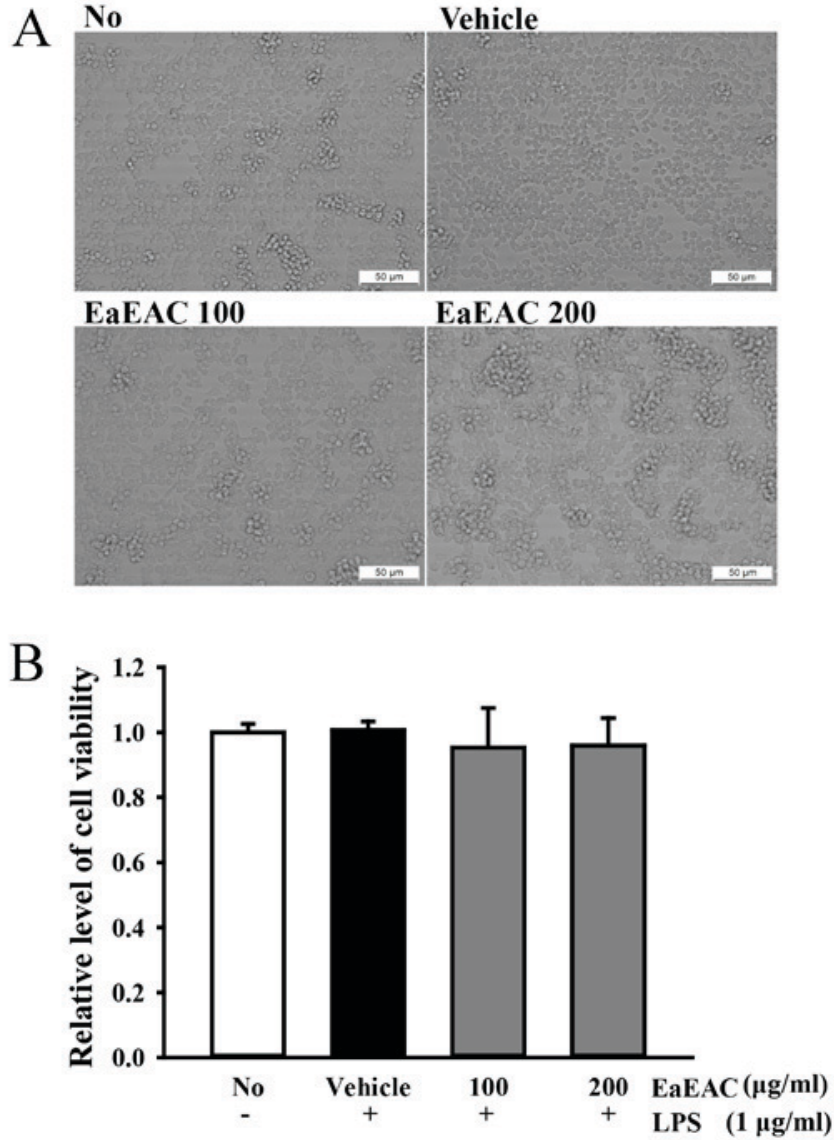

Figure 2. Toxicity of EaEAC. (A) Cell morphologies were observed under an inverted light microscope at $\mathrm{x} 400$ magnification following incubation with LPS and 0 (vehicle), 100 or $200 \mu \mathrm{g} / \mathrm{ml} \mathrm{EaEAC} \mathrm{in} \mathrm{dimethyl} \mathrm{sulfoxide}$ for $24 \mathrm{~h}$. (B) Cell viability of RAW264.7 cells treated with EaEAC + LPS was determined by 3-[4,5-dimethylthiazol-2-yl]-2,5-diphenyltetrazolium bromide (MTT) assay. Values are presented as the mean \pm standard deviation of three replicates. NC, untreated control; EaEAC, ethyl acetate extract from Asparagus cochinchinesis root; LPS, lipopolysaccharide.

Effects of EaEAC on the expression of inflammatory cytokines. EaEAC-induced alterations to the mRNA expression levels of pro-inflammatory (TNF- $\alpha$ and IL-1 $\beta$ ) and anti-inflammatory (IL-10 and IL-6) cytokines in LPS-activated RAW264.7 cells were then investigated by semi-quantitative RT-PCR. The mRNA levels of the cytokines were significantly increased in the vehicle + LPS-treated group compared with the NC group $(\mathrm{P}=0.002$; Fig. 4A). Pretreatment with EaEAC had no significant effect on the mRNA expression levels of TNF- $\alpha$ at either 100 or $200 \mu \mathrm{g} / \mathrm{ml}$ (Fig. 4A). However, pretreatment with 100 and $200 \mu \mathrm{g} / \mathrm{ml} \mathrm{EaEAC} \mathrm{significantly} \mathrm{reduced} \mathrm{mRNA} \mathrm{expres-}$ sion of IL-1 $\beta$ ( $\mathrm{P}=0.003$ and $\mathrm{P}=0.003$, respectively; Fig. 4A), while $200 \mu \mathrm{g} / \mathrm{ml}$ EaEAC significantly reduced mRNA levels of IL-10 ( $\mathrm{P}=0.008)$ and IL-6 $(\mathrm{P}=0.002)$ compared with vehicle + LPS (Fig. 4A).

The concentration of IL- 6 in the culture supernatant of LPS-activated RAW264.7 cells was also measured by ELISA. Similarly to the mRNA expression levels, the concentration of IL-6 was significantly increased in the Vehicle + LPS treated group compared with the $\mathrm{NC}$ group $(\mathrm{P}=0.005$; Fig. 4B). However, no significant differences were observed between the Vehicle + LPS group and the EaEAC + LPS groups, despite a
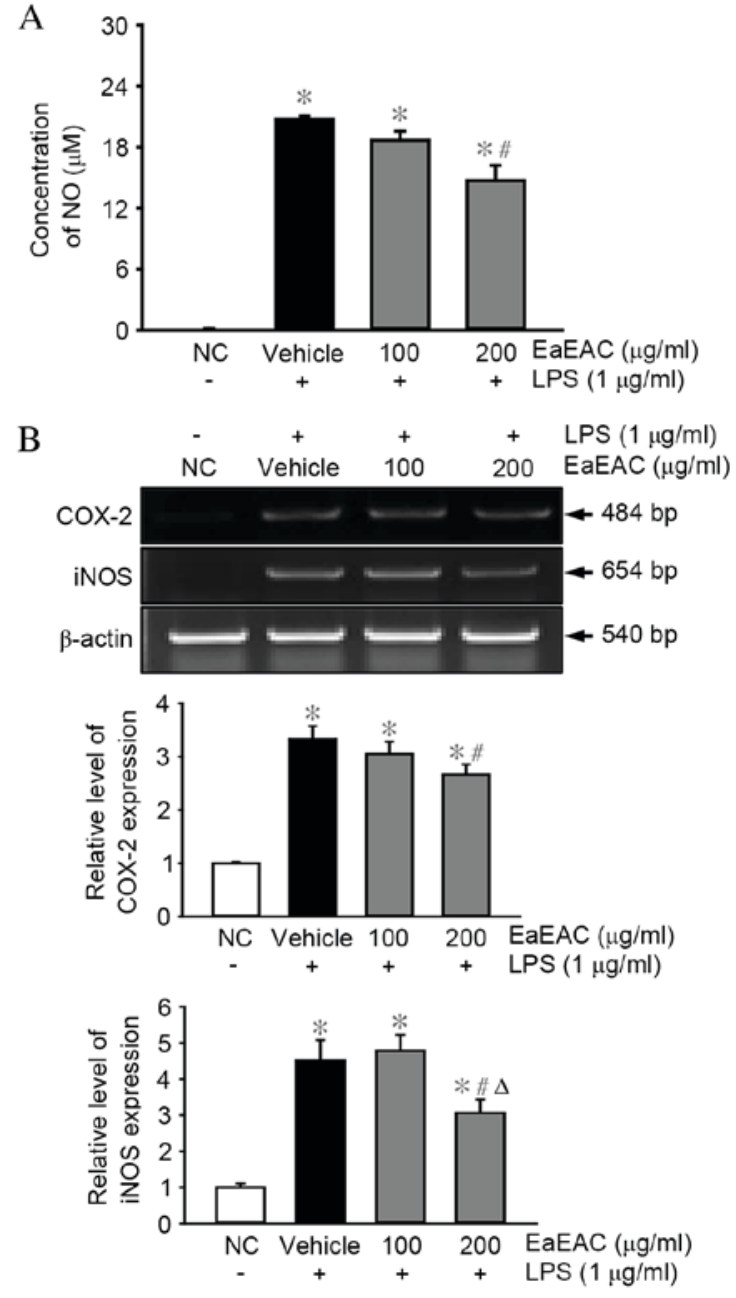

Figure 3. Determination of NO concentration, COX-2 and iNOS expression. (A) NO concentration was determined using supernatant collected from LPS-activated RAW264.7 cells treated with 0 (vehicle), 100 or $200 \mu \mathrm{g} / \mathrm{ml}$ EaEAC. (B) COX-2 and iNOS mRNA transcript levels in the NC, vehicle + LPS and EaEAC + LPS treated groups were examined by reverse transcription-quantitative polymerase chain reaction (RT-qPCR) using transcript-specific primers. Values are presented as the mean \pm standard deviation of three replicates. ${ }^{*} \mathrm{P}<0.05$ vs. $\mathrm{NC} ;{ }^{*} \mathrm{P}<0.05$ vs. vehicle + LPS-treated group; ${ }^{\Delta} \mathrm{P}<0.05$ vs. $100 \mu \mathrm{g} / \mathrm{ml}$ EaEAC + LPS-treated group. NO, nitric oxide; $\mathrm{NC}$ untreated control; EaEAC, ethyl acetate extract from Asparagus cochinchinesis root; LPS, lipopolysaccharide; COX-2, cyclooxygenase-2; iNOS, inducible nitric oxide synthase.

trend towards lower concentrations following EaEAC treatment (Fig. 4B). EaEAC pretreatment is, therefore, suggested to suppress enhanced anti- and pro-inflammatory cytokine expression in RAW264.7 cells stimulated by LPS treatment.

Effects of EaEAC on MAPK signaling. The MAPK pathway is critical in the regulation of cell growth and differentiation, and in the control of cellular responses to various cytokines and stresses (33). To investigate whether EaEAC pretreatment influences activation of the MAPK pathway, the phosphorylation levels of ERK, JNK and p38 were assessed in LPS-stimulated RAW264.7 cells by western blotting (Fig. 5A and B). Levels of phosphorylated ERK and p38 were significantly higher in cells stimulated with LPS (vehicle + LPS group) compared with untreated control cells $(\mathrm{P}=0.001$ and $\mathrm{P}=0.002$, respectively; Fig. 5B). EaEAC pretreatment significantly suppressed 
A
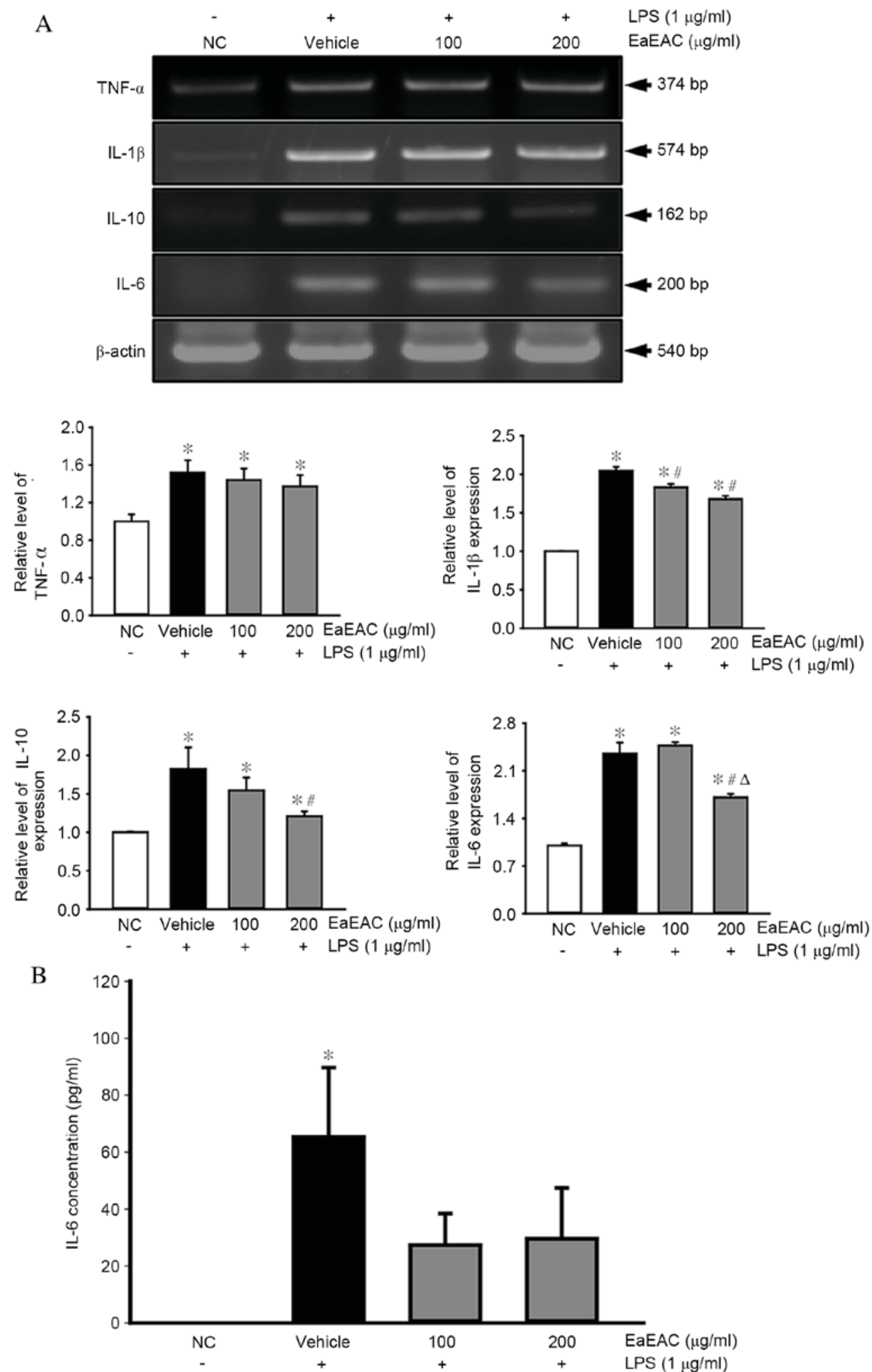

Figure 4. Analysis of pro- and anti-inflammatory cytokine expression. Following treatment of RAW264.7 cells with LPS and 0 (vehicle), $100 \mathrm{or} 200 \mu \mathrm{g} / \mathrm{ml}$ of EaEAC, (A) IL-1 $\beta$, TNF- $\alpha$, IL- 6 and IL-10 mRNA levels were assessed by semi-quantitative reverse transcription polymerase chain reaction using transcript-specific primers, and (B) IL-6 concentration was detected using an enzyme-linked immunosorbent assay kit with a minimum detection threshold of $9.3 \mathrm{pg} / \mathrm{ml}$. Values are presented as the mean \pm standard deviation of three replicates. ${ }^{*} \mathrm{P}<0.05 \mathrm{vs}$. $\mathrm{NC} ;{ }^{*} \mathrm{P}<0.05$ vs. vehicle $+\mathrm{LPS}$-treated group; ${ }^{\wedge} \mathrm{P}<0.05$ vs. $100 \mu \mathrm{g} / \mathrm{ml}$ EaEAC + LPS-treated group. LPS, lipopolysaccharide; NC, untreated control; EaEAC, ethyl acetate extract from A. cochinchinesis root; TNF- $\alpha$, tumor necrosis factor- $\alpha$; IL, interleukin.

the LPS-induced phosphorylation of ERK at concentrations of $100(\mathrm{P}=0.002)$ and $200 \mu \mathrm{g} / \mathrm{ml}(\mathrm{P}=0.003)$ compared with the vehicle + LPS group (Fig. 5B). JNK phosphorylation was also suppressed by $100(\mathrm{P}=0.015)$ and $200 \mu \mathrm{g} / \mathrm{ml}$ EaEAC $(\mathrm{P}=0.033)$ compared with the vehicle + LPS group (Fig. $5 \mathrm{~B})$, however, the JNK phosphorylation level was not induced 

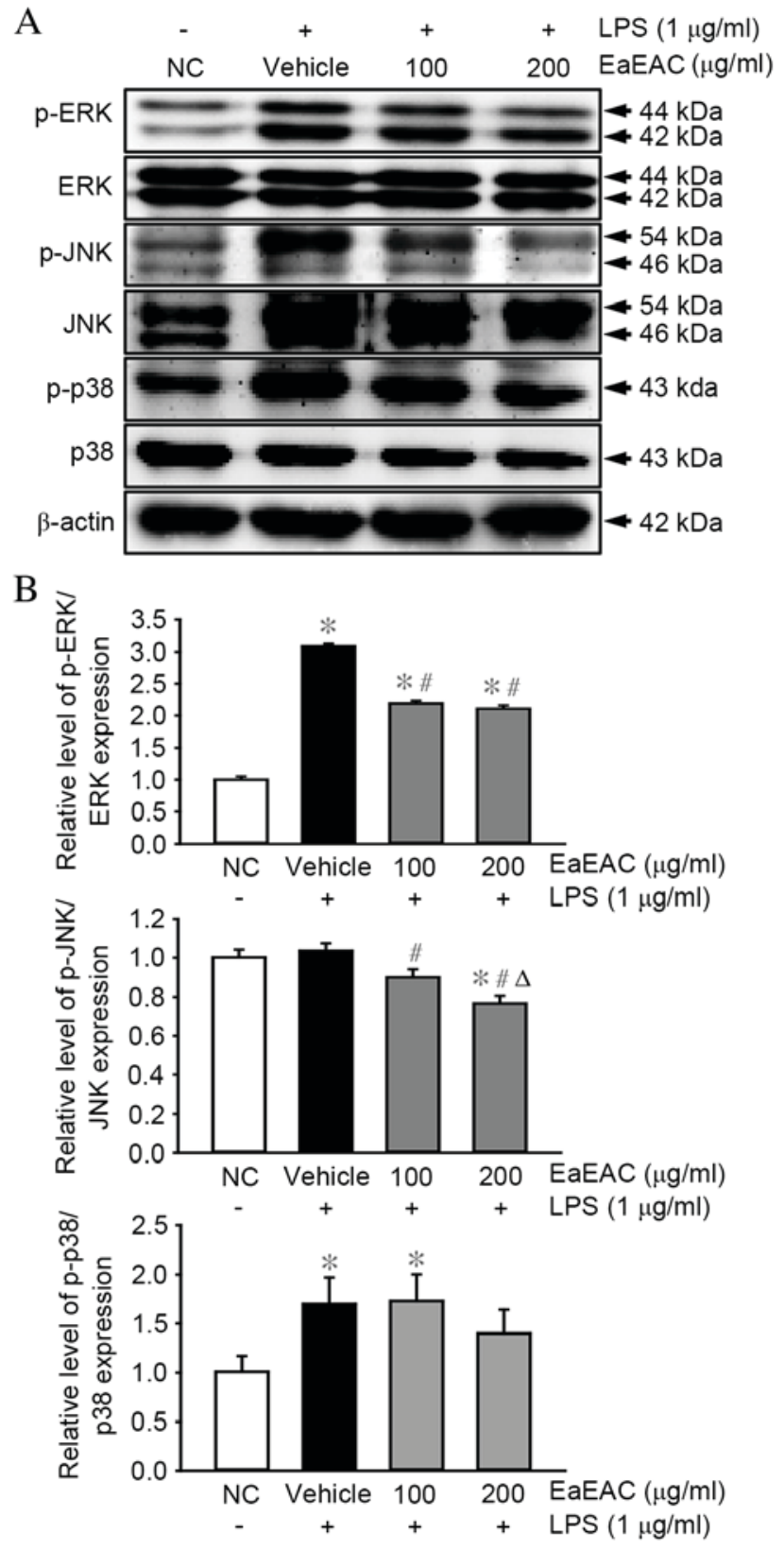

Figure 5. Activation of the mitogen-activated protein kinase signaling pathway proteins ERK, JNK, and p38. (A) p-ERK, ERK, p-JNK, JNK, p38, p-p38 and $\beta$-actin protein expression was assessed by western blot following stimulation of RAW264.7 cells with LPS and 0 (vehicle), 100 or $200 \mu \mathrm{g} / \mathrm{ml}$ of EaEAC. (B) Band intensity was determined using an imaging densitometer and expression levels calculated relative to the intensity of $\beta$-actin. Values are presented as the mean \pm standard deviation of three replicates. ${ }^{*} \mathrm{P}<0.05$ vs. $\mathrm{NC} ;{ }^{*} \mathrm{P}<0.05$ vs. vehicle + LPS-treated group; ${ }^{\mathrm{P}} \mathrm{P}<0.05$ vs. $100 \mu \mathrm{g} / \mathrm{ml}$ EaEAC + LPS-treated group. LPS, lipopolysaccharide; NC, untreated control; EaEAC, ethyl acetate extract from Asparagus cochinchinesis root; p-, phosphorylated; ERK, extracellular signal-regulated kinase; JNK, c-Jun N-terminal kinase.

by LPS stimulation, as demonstrated by the non-significant difference between the NC and vehicle + LPS group (Fig. 5B). EaEAC pretreatment resulted in no significant difference in LPS-induced phosphorylation of p38 at concentrations of 100 or $200 \mu \mathrm{g} / \mathrm{ml}$ compared with the vehicle + LPS group (Fig. 5B). Therefore, EaEAC attenuated the enhanced phosphorylation of some MAPK proteins in LPS-stimulated RAW264.7 macrophage cells.
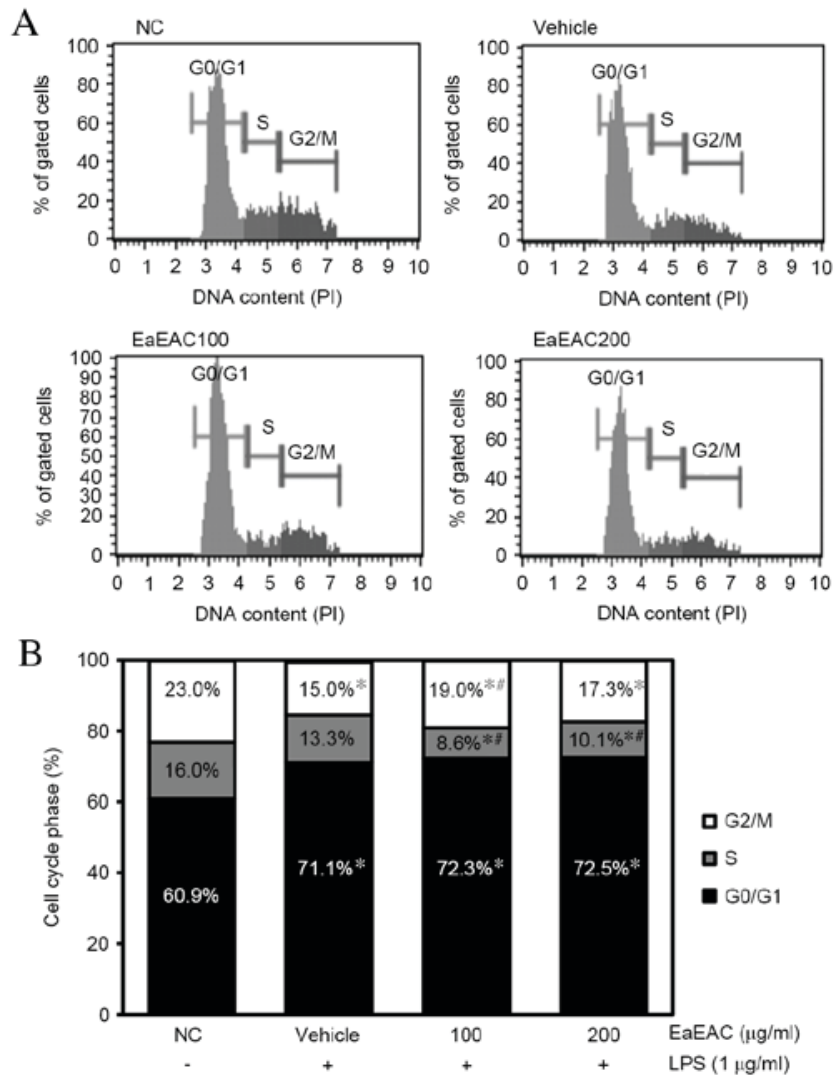

Figure 6. Cell cycle analysis. The cell cycle distribution was determined by flow cytometric analysis of the DNA content of nuclei of RAW264.7 cells following staining with PI. After treatment with EaEAC + LPS, the number of cells in the G0/G1, S and G2/M stage was determined. (A) Fluorescence-activated cell sorting analysis and (B) the relative percentage of cells in each cell cycle phase (G0/G1, S and G2/M). " $\mathrm{P}<0.05$ vs. NC. ${ }^{\text {PP }}<0.05$ vs. Vehicle + LPS treated group. PI, propidium iodide; EaEAC, ethyl acetate extract from Asparagus cochinchinesis root; LPS, lipopolysaccharide; $\mathrm{NC}$, untreated control.

Effect of EaEAC on regulation of the cell cycle. To examine the effect of EaEAC treatment on the cell cycle, the number of cells in each stage of the cell cycle was counted (Fig. 6A and B). The number of cells in the G0/G1 stage was increased in the vehicle + LPS group compared with untreated control cells $(\mathrm{P}=0.003$; Fig. $6 \mathrm{~B})$, whereas those in the $\mathrm{S}$ and $\mathrm{G} 2 / \mathrm{M}$ stage were decreased $(\mathrm{P}=0.001$; Fig. $6 \mathrm{~B})$. However, a significant increase in the number of cells in the G2/M stage was induced by treatment with $100 \mu \mathrm{g} / \mathrm{ml}$ EaEAC compared with the vehicle + LPS group $(\mathrm{P}=0.023$; Fig. 6B), and a similar but non-significant trend towards increased $\mathrm{G} 2 / \mathrm{M}$ stage cells was induced by treatment with $200 \mu \mathrm{g} / \mathrm{ml} \mathrm{EaEAC} \mathrm{(Fig.} \mathrm{6B).}$ A significant decrease in the number of $\mathrm{S}$ stage cells was also observed following treatment with $100(\mathrm{P}=0.05)$ and $200 \mu \mathrm{g} / \mathrm{ml}$ EaEAC $(\mathrm{P}=0.008)$ compared with the vehicle + LPS (Fig. 6B). EaEAC treatment was, therefore, demonstrated to induce arrest of the cell cycle in the G2/M stage and stimulate progression from the $\mathrm{S}$ stage to the $\mathrm{G} 2 / \mathrm{M}$ stage.

Inhibitory effects of EaEAC treatment on ROS production. Finally, the inhibitory effects of EaEAC against LPS-induced ROS production in RAW264.7 macrophage cells were determined using a fluorescent oxidation-sensitive dye, DCFH-DA, to measure ROS levels. ROS production increased rapidly 


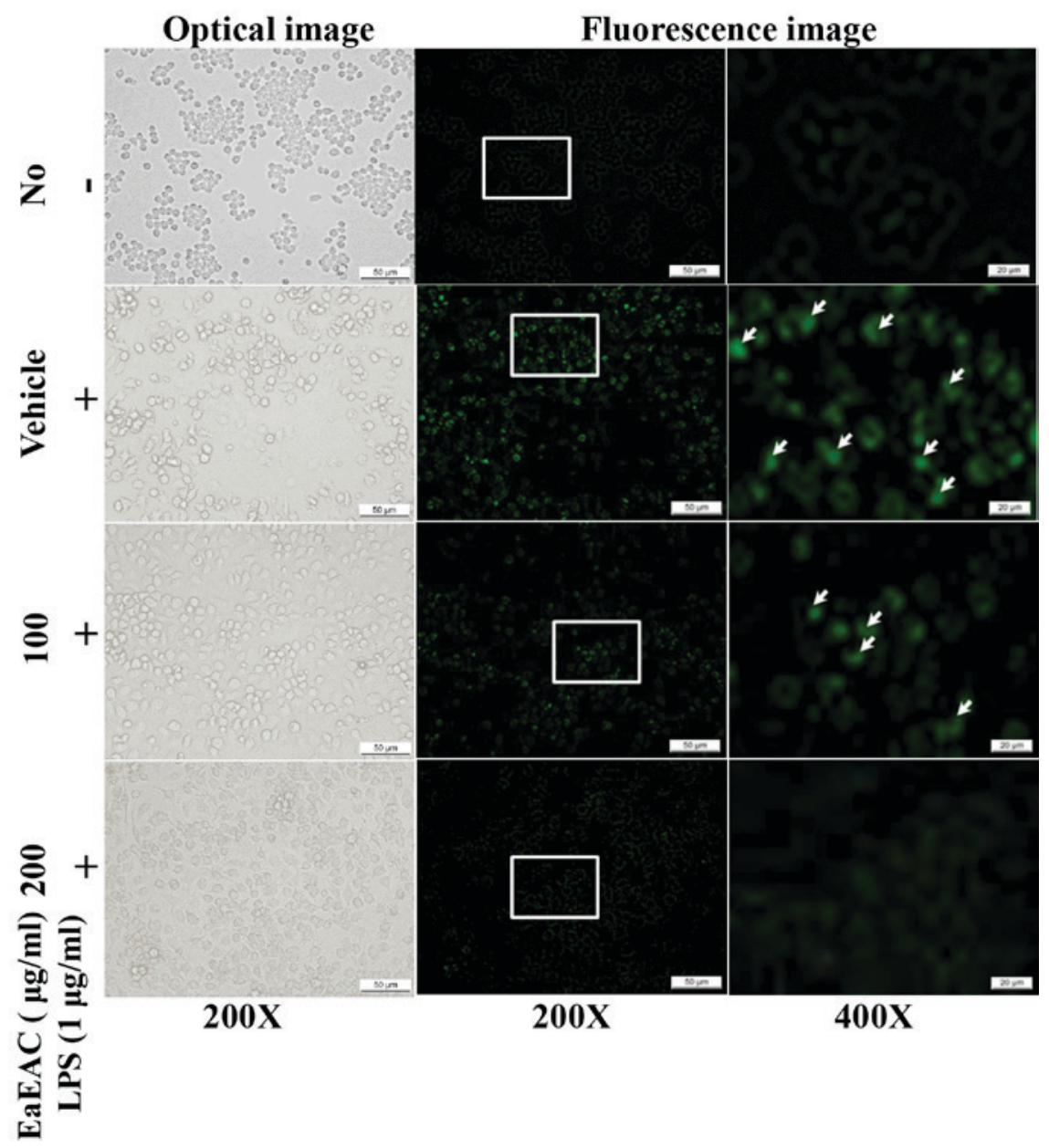

Figure 7. Determination of intracellular reactive oxygen species production. Cells were pretreated with LPS and 0 (vehicle), $100 \mathrm{or} 200 \mu \mathrm{g} / \mathrm{ml}$ of EaEAC in dimethyl sulfoxide, then treated with DCFH-DA. Optical images (left column) were observed by light microscopy, and green fluorescence in cells was observed by fluorescence microscopy. Boxed cells in each x 200 magnification image (center column) were further examined under x 400 magnification (right column). Arrows indicate cells stained with DCFH-DA. DCFH-DA, 2',7'-dichlorodihydrofluorescein diacetate; NC, untreated control; EaEAC, ethyl acetate extract from Asparagus cochinchinesis root; LPS, lipopolysaccharide.

in the vehicle + LPS-treated group compared with the NC group. However, the level of ROS production decreased in an apparently concentration-dependent manner, despite cell morphologies remaining consistent. Therefore, increased ROS levels induced by LPS stimulation were effectively suppressed by EaEAC pretreatment.

\section{Discussion}

Extracts of $A$. cochinchinensis roots have been used in Korea to treat neuro-inflammatory and skin-inflammatory diseases for many years $(1,25,27)$. Several studies have, therefore, focused on A. cochinchinensis to develop therapies against lung-inflammatory disease $(28,34)$. In an effort to identify candidate natural products for the treatment of chronic lung disease and examine the mechanism of action, the present study investigated the therapeutic effects of EaEAC in LPS-activated RAW264.7 cells. EaEAC was demonstrated to significantly suppress inflammatory responses through decreased NO, COX-2, iNOS, IL-6, IL-10 and IL-1 $\beta$ expression levels, and attenuation of ROS production in LPS-activated RAW264.7 macrophages.
LPS is the major component of the external membrane of gram-negative bacteria, and an important molecule in the pathogenesis of sepsis and septic shock. LPS has also been widely used as a prototypical endotoxin to activate numerous cell types, including monocytes, dendritic cells, macrophages and B cells $(35,36)$. Among these cells, macrophages are crucial for regulating NO, TNF- $\alpha$, and IL-6 production, which mediate the development of various inflammatory diseases, including sepsis-related multiple organ dysfunction/multiple organ failure, microbial infection, acute brain/lung/hepatic/renal injuries, neurodegenerative disorders, tumorigenesis, osteoporosis/osteonecrosis, and cardiovascular, metabolic and autoimmune diseases (37-39). Furthermore, various concentrations of LPS (50 ng/ml to $10 \mu \mathrm{g} / \mathrm{ml})$ have been applied to activate RAW264.7 cells (40-42). Preliminary data from the present study demonstrated that an inflammatory response was induced in RAW264.7 cells stimulated with 0.1, $0.5,1.0$ and $1.5 \mu \mathrm{g} / \mathrm{ml}$ LPS (data not shown). A concentration of $1 \mu \mathrm{g} / \mathrm{ml}$ LPS was, therefore, selected as the optimal concentration for activation of macrophages in subsequent experiments.

NO, which include nitroglycerine and amyl nitrite precursor, are considered to be important cellular signaling 
molecules in various mammalian physiological and pathological processes (33). NO is produced by NOS in the majority of organisms, including bacteria, fungi and mammals. In humans, NO is primarily produced by iNOS in phagocytic cells during an immune response (43). LPS-induced NO production in BV-2 cells has previously been demonstrated to be significantly suppressed by three compounds originating from A. cochinchinensis: Aspacochinoside $\mathrm{O}$, Aspacochinoside $\mathrm{P}$ and 3- $O-\beta$-D-xylopyranosyl $(1 \rightarrow 4)$-[ $\beta$-D-glucopyranosyl $(1 \rightarrow 2)]-\beta$-D-glucopyranosyl-26- $O$ - $\beta$-D-glucopyranosyl-(25S)$5 \beta$-furostane-3 $\beta, 22 \alpha, 26$-triol (44). The present study demonstrated similar inhibitory effects on NO production, although the cell line and solvent used for extraction in the studies differed. EaEAC pretreatment induced the restoration of iNOS and COX-2 transcription levels in LPS-activated macrophage cells. The results of the current study suggest that the inhibitory effects of EaEAC on LPS-stimulated NO production are a result of iNOS and COX-2 transcriptional suppression. However, additional research is required to determine the key compounds within EaEAC that are responsible for the regulation of $\mathrm{NO}$ production.

Secretion of cytokines, including interleukins, interferon, colony stimulating factors and numerous growth factors regulate the differentiation, proliferation and development of cells (45). The pro-inflammatory cytokines secreted by stimulated macrophages are important in inflammatory diseases, including sepsis and arthritis $(46,47)$. Furthermore, extracts from A. cochinchinensis have previously been demonstrated to effectively regulate the expression of various cytokines; the increase of TNF- $\alpha$ secretion in astrocytes induced by substance P + LPS and ethanol treatment was significantly inhibited by ethanol extracts (70\%) of A. cochinchinensis (ACE) in a dose dependent manner $(21,25)$. Production of pro-inflammatory cytokines, including IL- $1 \beta$ and TNF- $\alpha$ has also been previously demonstrated to be suppressed by ACE in mice with phorbol ester-induced dermatitis (27). In the present study, the transcript and protein levels of proand anti-inflammatory cytokines in RAW264.7 cells were measured following EaEAC + LPS treatment, revealing similar suppressive activities compared with previous studies, despite certain differences in the reduction rate and the composition of the extracts.

To the best of our knowledge, the present study presents the first evidence of the therapeutic effect of EaEAC in LPS-activated RAW264.7 cells accompanied by alterations in MAPK signaling and the cell cycle. MAPKs are important in the regulation of cell growth and differentiation, and in the control of cellular responses to cytokines and stresses (48). In several previous studies, the expression levels of three major members of the MAPK signaling pathway, JNK, ERK and p38, were significantly increased by LPS treatment in macrophage cells $(49,50)$. LPS also increased the expression of several inflammatory genes, including TNF- $\alpha$, IL- 6 , iNOS and COX-2, through regulation of MAPKs $(51,52)$. Furthermore, pathological conditions, including inflammation and oxidative stress, have been demonstrated to induce alteration of the cell cycle in numerous diseases $(53,54)$. Certain natural products have also been previously demonstrated to induce alteration of MAPK expression and the cell cycle in RAW264.7 cells. For example, triterpene extract from G. lucidum suppressed the LPS-induced phosphorylation of ERK1/2 and JNK, and arrested these cells at the G0/G1-M stage (55). Wild grape seed procyanidins inhibited the LPS-induced phosphorylation of p38 (56), and Rhus verniciflua Stokes arrested RAW264.7 cells at the G1 stage of the cell cycle (57). In the present study, EaEAC inhibited the phosphorylation of three members of the MAPK signaling pathway and arrested the cell cycle at the G2/M stage. The results of the present study were similar to those of previous studies, although certain differences in the suppression of MAPK signaling were observed. These differences may be due to factors including the innate composition of the extracts and key molecules within the herbal medicine.

Oxidative stress, cell dysfunction and, ultimately, apoptosis and necrosis are induced by excessive production of ROS (58). The activity of SOD and the content of MDA have been demonstrated to be differentially regulated by the roots and stems of A.cochinchinensis, and polysaccharide and aqueous extracts of $A$. cochinchinensis roots increased SOD activity, but decreased MDA content (59). By contrast, A. cochinchinensis stem extracts decreased SOD activity and enhanced MDA accumulation in the brains and livers of mice (1). Similar effects on anti-oxidant state were detected in the present study: ROS production was increased in the vehicle + LPS-treated group, but was recovered in a dose dependent manner in the EaEAC + LPS-treated group, therefore providing additional evidence that the roots of $A$. cochinchinensis have anti-oxidant activity and may suppress ROS production. In summary, the present study suggests that EaEAC may suppress inflammatory responses in macrophages through stimulation of anti-inflammatory effects, decreased pro-inflammatory cytokine expression and inhibition of ROS production. The inhibitory effects of EaEAC were observed to be associated with attenuation of the enhanced phosphorylation of MAPK proteins following LPS treatment. The MAPK signaling pathway regulates the transcription of a number of genes associated with inflammation, thus, its inhibition by EaEAC offers a potential approach for the treatment of severe inflammatory disease.

\section{Acknowledgements}

This study was supported by grants to Professor Dae Youn Hwang from the Korea Institute of Planning Evaluation for Technology of Food, Agriculture, Forestry and Fisheries (grant no. 114034-03-1-HD030).

\section{References}

1. Xiong DS, Yu LX, Yan X, Guo C and Xiong Y: Effects of root and stem extracts of Asparagus cochinchinensis on biochemical indicators related to aging in the brain and liver of mice. Am J Chinese Med 39: 719-726, 2011.

2. Xiao PG: Modern Chinese material medica. Chemical Industry Press, Beijing, p150, 2002.

3. Liu YZ, Qu FY and Zhang PX: Effect of chloroform extract of Tiandong on the brain antioxidation of D-galatose-induced senile mice. Heilongjiang Med Pharm 24: 7-8, 2001.

4. Ni JM, Zhao R and Wang R: Comparison on amino acid content in prepared and unprepared Asparagus cochinchinensis. Chin Tradit Herb Drugs 23: 182-183, 1992.

5. Tenji K and Junzo S: Studies on the constituents of Asparagi Radix. I. On the structures of furostanol oligosides of Asparagus cochinchinensis (LOUREIO) MERRILL. Chem Pharm Bull 27: 3086-3094, 1979. 
6. Liang ZZ, Aquino R, De Simone F, Dini A, Schettino O and Pizza C: Oligofurostanosides from Asparagus cochinchinensis. Planta Med 54: 344-346, 1988.

7. Yang YC, Huang SY and Shi JG: Two new furostanol glycosides from Asparagus cochinchinensis. Chin Chem Lett 13: 1185-1188, 2002.

8. Cong PZ and Keman S: Handbook of analytical chemistry-mass volume. Chemical Industry Publishing House 2, Beijing, pp296-298, 2000.

9. Gong YH: ${ }^{13} \mathrm{C}$ NMR chemical shifts of natural organic compounds. Yunnan Science and Technology Publishing House Kunming 2: 252, 1986.

10. Yang MH: Steroidal sapogenins of dioscorea. Chin Tradit Herb Drugs 12: 43-44, 1981.

11. Xu CL, Chen HS and Tan XQ: Studies on the active constituents of Asparagi Radix. Nat Prod Res Dev 17: 128-130, 2005.

12. Shen Y, Chen HS and Wang Q: Studies on chemical constituents of Asparagus cochinchinensis (II). J Second Med Univ 28: 1241-1244, 2007.

13. Shen Y, Xu Cl, Xuan WD, Li HL, Liu RH, Xu XK and Chen HS: A new furostanol saponin from Asparagus cochinchinensis. Arch Pharm Res 34: 1587-1591, 2011.

14. Li XN, Chu C, Cheng DP, Tong SQ and Yan JZ: Norlignans from Asparagus Cochinchinensis. Nat Prod Commun 7: 1357-1358, 2012.

15. Zhu GL, Hao Q, Li RT and Li HZ: Steroidal saponins from the roots of Asparagus cochinchinensis. Chin J Nat Med 12: 213-217, 2014.

16. Li M, Fei Y and Wang JK: Studies on pharmacologic effects of Radix Asparagi. LiShiZhen Med Mater Med Res 16: 580-582, 2005.

17. Qu FY, Wei XD, Li SL, Wang YM and Bai SG: Experimental study of Asparagus cochinchinensis delay aging. Acta Chin Med Pharm 2: 68-70, 1999.

18. Zhao YJ, Meng XL, Li XL and Qu FY: Influence of Radix Asparagi nano-pharmaceutics on NOS, NO, LPF of aging mice. Chin Wild Plant Resour 24: 49-51, 2005.

19. Wen JY, Li Y, Ding SS and Li QH: Nine Pharmacological screening of medicinal plants of China Liliaceae Asparagus. J Acta Acad Med Shanghai 20: 107-111, 1993.

20. Luo J, Long Q, Li C, Li L and Huang N: Inhibitory effects of ALWB and ACM on mice bearing tumor. J GuiYang Med Coll 25: 15-16, 2000.

21. Koo HN, Jeong HJ, Choi JY, Choi SD, Choi TJ, Cheon YS, Kim KS, Kang BK, Park ST, Chang CH, et al: Inhibition of tumor necrosis factor-alpha-induced apoptosis by Asparagus cochlnchinensis in Hep G2 cells. J Ethnopharmacol 73: 137-143, 2000.

22. Yu FR, Lian XZ and Guo HY: Effect of lucid asparagus extract on the regulation of blood sugar. Chin J Clin Rehabil 10: 57-59, 2006.

23. Jun L, Qingde L, Chengxiu L, Ling L, Nenghui H, Min N and Peixian T: Comparison of antitussive, expectorant and anti-asthmatic effect between ALWB and ACM. J GuiYang Med Coll 23: $132-134,1998$

24. Lv B and Liu WZ: Aspartate treatment of hemodialysis patients with hypertension in 22 cases. J Tradit Chin Med 19: 43-44, 2004

25. Kim HM, Lee E, Lim T, Jung J and Lyu Y: Inhibitory effect of Asparagus cochinchinensis on tumor necrosis factor-alpha secretion from astrocytes. Int J Immunopharmacol 20: 153-162, 1998.

26. Jian R, Zeng KW, Li J, Li N, Jiang Y and Tu P: Anti-neuroinflammatory constituents from Asparagus cochinchinensis. Fitoterapia 84: 80-84, 2013.

27. Lee DY, Choo BK, Yoon T, Cheon MS, Lee HW, Lee YA and Kim HK: Anti-inflammatory effects of Asparagus cochinchinensis extract in acute and chronic cutaneous inflammation. J Ethnopharmacol 121: 28-34,2009.

28. Jung KH, Choi HL, Park SJ, Lee GH, Kim MR, Min JK, Min BI and Bae $\mathrm{H}$ : The effects of the standardized herbal formula PM014 on pulmonary inflammation and airway responsiveness in a murine model of cockroach allergen-induced asthma. J Ethnopharmacol 155: 113-122, 2014.

29. Chi H, Barry SP, Roth RJ, Wu JJ, Jones EA, Bennett AM and Flavell RA: Dynamic regulation of pro- and anti-inflammatory cytokines by MAPK phosphatase 1 (MKP-1) in innate immune responses. Proc Natl Acad Sci USA 103: 2274-2279, 2006.

30. Oh H, Ko EK, Kim DH, Jang KK, Park SE, Lee HS and Kim YC: Secoiridoid glucosides with free radical scavenging activity from the leaves of Syringa dilatata. Phytother Res 17: 417-419, 2003.
31. Jie S, Xueji Z, Mark B and Harry F: Measurement of nitric oxide production in biological systems by using griess reaction assay. Sensors 3: 276-284, 2003

32. Kim JE, Park SH, Kwak MH, Go J, Koh EK, Song SH, Sung JE, Lee HS, Hong JT and Hwang DY: Characterization of changes in global genes expression in the distal colon of loperamide-induced constipation SD rats in response to the laxative effects of Liriope platyphylla. PLoS One 10: e0129664, 2015.

33. Hou YC, Janczuk A and Wang PG: Current trends in the development of nitric oxide donors. Curr Pharm Des 5: 417-441, 1999.

34. Lee JH, Lim HJ, Lee CW, Son KH, Son JK, Lee SK and Kim HP: Methyl protodioscin from the roots of Asparagus cochinchinensis attenuates airway inflammation by inhibiting cytokine production. Evid Based Complement Alternat Med 2015: 640846, 2015.

35. Rietschel ET, Kirikae T, Schade FU, Mamat U, Schmidt G Loppnow H, Ulmer AJ, Zähringer U, Seydel U and Di Padova F: Bacterial endotoxin: Molecular relationships of structure to activity and function. FASEB J 8: 217-25, 1994.

36. Stewart I, Schluter PJ and Shaw GR: Cyanobacterial lipopolysaccharides and human health-a review. Environ Health 5: 7, 2006.

37. Fujiwara $\mathrm{N}$ and Kobayashi K: Macrophages in inflammation. Curr Drug Targets Inflamm Allergy 4: 281-286, 2005.

38. Dalmas E, Tordjman J, Guerre-Millo $M$ and Clément $K$ : Macrophages and inflammation. In: Adipose Tissue Biology. Symonds ME (ed.) Springer, New York, NY, pp167-193, 2012

39. Jou IM, Lin CF, Tsai KJ and Wei SJ: Macrophage-mediated inflammatory disorders. Mediators Inflamm 2013: 316482, 2013

40. Yang GY, Liao J, Li C, Chung J, Yurkow EJ, Ho CT and Yang CS: Effect of black and green tea polyphenols on c-jun phosphorylation and $\mathrm{H}(2) \mathrm{O}(2)$ production in transformed and non-transformed human bronchial cell lines: Possible mechanisms of cell growth inhibition and apoptosis induction. Carcinogenesis 21: 2035-2039, 2000.

41. Lee SJ, Kang HY, Lee SY and Hur SJ: Green tea polyphenol Epigallocatechin-3-O-Gallate attenuates lipopolysaccharide-induced nitric oxide production in RAW264.7 cells. J Food Nutr Res 2: 425-428, 2014.

42. Hashimoto $\mathrm{K}$ and Sakagami $\mathrm{H}$ : Induction of apoptosis by Epigallocatechin gallate and autophagy inhibitors in a mouse macrophage-like cell line. Anticancer Res 28: 1713-1718, 2008.

43. Kamijo R, Gerecitano J, Shapiro D, Green SJ, Aguet M, Le J and Vilcek J: Generation of nitric oxide and clearance of interferon-gamma after BCG infection are impaired in mice that lack the interferon-gamma receptor. J Inflamm 46: 23-31, 1995.

44. Jian R, Zeng KW, Li J, Li N, Jiang $Y$ and Tu $P$ Anti-neuroinflammatory constituents from Asparagus cochinchinensis. Fitoterapia 84: 80-84, 2013.

45. Scheller J, Chalaris A, Schmidt-Arras D and Rose-John S: The pro- and anti-inflammatory properties of the cytokine interleukin-6. Biochim Biophys Acta 1813: 878-888, 2011.

46. Szabó C: Role of nitric oxide in endotoxic shock. An overview of recent advances. Ann N Y Acad Sci 851: 422-425, 1998

47. Martel-Pelletier J, Pelletier JP and Fahmi H: Cyclooxygenase-2 and prostaglandins in articular tissues. Semin Arthritis Rheum 33: 155-167, 2003.

48. Vanden Berghe W, Plaisance S, Boone E, De bosscher K, Schmitz ML, Fiers W and Haegeman G: p38 and extracellular signal-regulated kinase mitogen-activated protein kinase pathways are required for nuclear factor-kappaB p65 transactivation mediated by tumor necrosis factor. J Biol Chem 273: 3285-3290, 1998.

49. Weinstein SL, Sanghera JS, Lemke K, DeFranco AL and Pelech SL: Bacterial lipopolysaccharide induces tyrosine phosphorylation and activation of mitogen-activated protein kinases in macrophages. J Biol Chem 267: 14955-14962, 1992.

50. Comalada M, Xaus J, Valledor AF, López-López C Pennington DJ and Celada A: PKC epsilon is involved in JNK activation that mediates LPS-induced TNF-alpha, which induces apoptosis in macrophages. Am J Physiol Cell Physiol 285: C1235-C1245, 2003

51. Ulevitch RJ and Tobias PS: Receptor-dependent mechanisms of cell stimulation by bacterial endotoxin. Annu Rev Immunol 13: 437-457, 1995.

52. Weinstein SL, Sanghera JS, Lemke K, DeFranco AL and Pelech SL: Bacterial lipopolysaccharide induces tyrosine phosphorylation and activation of mitogen-activated protein kinases in macrophages. J Biol Chem 267: 14955-14962, 1992.

53. Kirouac L, Mathew $M$ and Padmanabhan J: Interplay between inflammation and cell cycle deregulation in Alzheimer's disease. JSM Alzheimer's Dis and Related Dementia 2: 1018, 2015. 
54. Stockley JA, Walton GM, Lord JM and Sapey E: Aberrant neutrophil functions in stable chronic obstructive pulmonary disease: The neutrophil as an immunotherapeutic target. Int Immunopharmacol 17: 1211-1217, 2013.

55. Dudhgaonkar S, Thyagarajan A and Sliva D: Suppression of the inflammatory response by triterpenes isolated from the mushromm Ganoderma lucidum. Int Immunopharmacol 9: 1272-1280, 2009.

56. Bak MJ, Truong VL, Kang HS, Jun MR and Jeong WS: Anti-inflammatory effect of procyanidins from wild grape (Vitis amurensis) seeds in LPS-induced RAW 264.7 cells. Oxid Med Cell Longev 2013: 409321, 2013.
57. Choi HS, Seo HS, Kim SR, Choi YK, Shin YC and Ko SG: Anti-inflammatory and anti-proliferative effect of herbal medicines (APR) in RAW264.7 cells. Mol Med Rep 9: 1569-1574, 2014.

58. Halliwell B: Reactive oxygen species and the central nervous system. J Neurochem 59: 1609-1623, 1992.

59. Xiong D, Yu LX, Yan X, Guo C and Xiong Y: Effects of root and stem extracts of Asparagus cochinchinensis on biochemical indicators related to aging in the brain and liver of mice. Am J Chin Med 39: 719-726, 2011. 